\title{
Attenuation of Drug-Induced Loss of Righting Reflex Response by Pretreatment with a Nitric Oxide Donor
}

\author{
Yuhua (Al) Wang ${ }^{1}$, Raymond M. Quock ${ }^{2}$ and Robert D. Keegan ${ }^{*, 3}$ \\ ${ }^{1}$ Graduate Program in Pharmacology/Toxicology and ${ }^{2}$ Department of Pharmaceutical Sciences, College of Pharmacy \\ and ${ }^{3}$ Department of Veterinary Clinical Sciences, College of Veterinary Medicine, Washington State University, \\ Pullman, WA 99164-6610, USA
}

\begin{abstract}
Background/Aims: The role of nitric oxide (NO) in general anesthetic drug action is controversial. The present study was carried out to determine the role of NO in the loss of righting reflex induced by injectable sedative and anesthetic drugs.

Methods: Under isoflurane anesthesia, male NIH Swiss mice received an intracerebroventricular microinjection of the NOdonor 3-morpholinosydnoimine (SIN-1) 30 min prior to an i.p. injection of chloral hydrate, sodium barbital, midazolam or ketamine/xylazine. Mice were monitored for onset and duration of loss of righting reflex (LORR).

Results: Pretreatment with SIN-1 reduced the mean duration of LORR induced by chloral hydrate, sodium barbital and midazolam but not ketamine/xylazine. Pretreatment with SIN-1 had no effect on the mean latency to LORR.

Conclusion: It is concluded that there may be a differential involvement of NO in the LORR response, depending upon whether the primary drug action is through $\mathrm{GABA}_{\mathrm{A}}$ or NMDA receptors.
\end{abstract}

Keywords: Nitric oxide, loss of righting reflex, chloral hydrate, sodium barbital, midazolam, ketamine/xylazine, mice.

\section{INTRODUCTION}

The role of nitric oxide (NO) in general anesthetic drug action is controversial. There is experimental evidence that a central N-methyl-D-aspartate-neuronal nitric oxide synthasecyclic GMP (NMDA-nNOS-cGMP) pathway is suppressed during inhalation anesthesia [1-3]. Inhibition of nitric oxide synthase (NO) enzyme activity reduces the minimum alveolar concentration (MAC) of inhalation general anesthetics $[4,5]$. There are also experimental findings that brain NOS activity is reduced in the presence of inhalation general anesthetics [6-8].

Whether NO might be involved in the anesthetic effects of injectable drugs is inconclusive at this time. The present study was carried out to determine the role of NO in druginduced loss of righting reflex (LORR) by NO preloading using an NO-donor.

\section{METHODS AND MATERIALS}

Approximately 150 male NIH Swiss mice, 20-30 g, were purchased from Harlan Laboratories (Indianapolis, Indiana) for these experiments, which were approved by the institutional animal care and use committee (IACUC) of Washington State University, and were conducted in accordance with The Guide for the Care and Use of Laboratory Animals, published by the U.S. National Institutes of Health (NIH Publication No. 85-23, revised 1996). Mice were housed five per cage in an on-campus

*Address correspondence to this author at the Department of Veterinary Clinical Sciences, College of Veterinary Medicine, Washington State University, P.O. Box 646610, Pullman, WA 99164-6610, USA; Tel: +1 509 335 0770; Fax: +1 509335 0880; E-mail: rdk@vetmed.wsu.edu animal facility, which is accredited by the Association for Assessment and Accreditation of Laboratory Animal Care (AAALAC. Food and water were available ad libitum. The facility was maintained on a 12-h light/dark cycle (lights on $0700-1900)$ under standard conditions $\left(22 \pm 1{ }^{\circ} \mathrm{C}\right.$ room temperature, $33 \%$ humidity). Mice were kept in the holding room for at least four days following arrival in the facility prior to use. Animals were used only one time, and all care was taken to minimize pain and discomfort in the experimental animals.

The following drugs were used in this research: 3morpholinosydnoimine (SIN-1), chloral hydrate, sodium barbital, midazolam and xylazine (all from Sigma Chemical Company, St. Louis, MO); ketamine (Ketaject ${ }^{\circledR}$, Phoenix Pharmaceutical, Inc., St. Joseph, MO). All drugs were prepared in $0.9 \%$ physiological saline solution.

Mice received an intracerebroventricular (i.c.v.) microinjection of SIN-1 or saline vehicle. The i.c.v. pretreatments were made using the microinjection technique of Haley and McCormick [9]. Briefly, mice were anesthetized with $\mathrm{IsoFlo}^{\mathbb{R}}$ (isoflurane, U.S.P., Abbott Laboratories, North Chicago, IL). A short incision was made along the midline of the scalp using a scalpel, and the skin was pulled back to expose the calvarium. The i.c.v. microinjection was made using a $10-\mu 1$ microsyringe (Hamilton, Reno, NV) with a 26-gauge cemented needle. The microsyringe was held vertically by hand at a point on the calvarium $2.0 \mathrm{~mm}$ lateral and $1.0 \mathrm{~mm}$ caudal from bregma to a depth of $-2.0 \mathrm{~mm}$ from the skull surface. Penetration was controlled by a large-bore needle through which the microsyringe needle was inserted through a largebore hypodermic needle which served as a collar to limit 
penetration of the microsyringe needle to $2.0 \mathrm{~mm}$. A volume of $5.0 \mu 1$ of drug solution was delivered directly into the lateral cerebral ventricle over $30 \mathrm{sec}$. Thirty min later, mice were treated i.p. with chloral hydrate $(300 \mathrm{mg} / \mathrm{kg})$, sodium barbital $(250 \mathrm{mg} / \mathrm{kg})$, midazolam $(75 \mathrm{mg} / \mathrm{kg})$ or ketamine $(100 \mathrm{mg} / \mathrm{kg}) / x y$ lazine $(15 \mathrm{mg} / \mathrm{kg})$. Doses of these drugs were taken from the scientific literature. There was no effort to identify equipotent doses of these drugs i.e. doses that would produce roughly the same onset or duration of LORR.

Upon the onset of sedation, each mouse was placed on its back in a V-shaped trough and monitored for its onset and duration of LORR, which was defined as the inability of a mouse to right itself within $30 \mathrm{sec}$. Recovery of the righting response was defined as the ability of a mouse to right itself twice within $60 \mathrm{sec}$. The duration of LORR was defined as the time interval between the loss and recovery of the righting response.

The onsets and durations of LORR induced by each sedative drug following i.c.v. pretreatment with SIN-1 or saline vehicle were compared using Student's t-test or, when appropriate, one way ANOVA. In all cases the level of significance was set at $\mathrm{p}<0.05$.

\section{RESULTS}

The results of this study are shown in Table 1. Different groups of mice were administered sedative or anesthetic drugs in the absence and presence of SIN-1. Pretreatment with SIN-1 failed to appreciably alter the onset of LORR for any of the drugs. The greatest change was a $10.8 \%$ lengthening of the onset to chloral hydrate-induced LORR, but this was not statistically significant. Pretreatment with SIN-1 significantly reduced the duration of LORR induced by chloral hydrate, sodium barbital and midazolam. However, pretreatment with SIN-1, even at the higher dose of $1.0 \mu \mathrm{g}$, did not significantly alter the duration of LORR induced by ketamine/xylazine.

\section{DISCUSSION}

The pretreatment of experimental animals with NOSinhibitors is reported to reduce the MAC value for inhalation general anesthetic drugs. Intravenous bolus treatment of rats with L-NAME, but not D-NAME, caused a dose-related reduction in MAC value for halothane; this reduction in MAC was immediately and completely reversed by infusion of L-arginine, but not by D-arginine, which suggests that inhibition of NO production by L-NAME was the underlying mechanism [4]. This finding was replicated in a number of laboratories that reported that L-NAME also reduced the MAC of isoflurane in mice, rats and rabbits [10-12], i.p. treatment with the neuronal-selective NOS-inhibitor 7nitroindazole reduced the MAC of isoflurane and halothane in mice and rats $[5,13,14]$, and 7-NI reduced the MAC of sevoflurane in rats [15]. In addition to having a MACreducing effect on inhalant anesthetics, inhibition of spinal NO production has been shown to contribute to the antinociceptive effects of isoflurane in rats [16]. There have some negative findings as well in that i.c.v., intrathecal and intravenous pretreatment with L-NAME failed to alter the MAC of halothane [17, 18]. It was also reported that the MAC for isoflurane was unaltered between wild-type and nNOS-KO mice [10].

Other research measured brain NOS enzyme activity following exposure to inhalation anesthetics. Rat cerebellar NOS activity - as determined by in vitro conversion of $\left[{ }^{14} \mathrm{C}\right] \mathrm{L}$-arginine to $\left[{ }^{14} 14 \mathrm{C}\right] \mathrm{L}$-citrulline-was significantly decreased by exposure to halothane and isoflurane $[6,12]$. Exposure to halothane decreased NOS activity from human polymorphonuclear leucocytes [8]. Exposure to halothane also reduced NOS activity in the spinal cord and locus coeruleus, as measured by nicotinamide adenine dinucleotide phosphate (NADPH) diaphorase histochemistry [13].

In addition, there are negative reports of any effect of halothane or isoflurane exposure on regional brain NOS enzyme activity in rat brain regions [19,20] or cerebellum slices [21]. More recent research has focused on anesthetic suppression of an NO-coupled stimulation of cyclic GMP formation by $\mathrm{N}$-methyl-D-aspartate rather than solely NO production [1-3].

There is also disagreement on whether NO might play a role in the actions of injectable anesthetic agents. Whereas rat cerebellar NOS enzyme activity - as determined by in vitro conversion of $\left[{ }^{14} \mathrm{C}\right] \mathrm{L}$-arginine to $\left[{ }^{14} \mathrm{C}\right] \mathrm{L}$-citrulline-was

Table 1. Effects of SIN-1 Pretreatment on Onset and Duration of Action of Drug-Induced Loss of Righting Reflex (LORR)

\begin{tabular}{|c|c|c|c|c|}
\hline Treatment Group (N) & \multicolumn{2}{|c|}{ Onset of LORR (sec) } & \multicolumn{2}{|c|}{ Duration of LORR (sec) } \\
\hline $\mathrm{SIN}-1+\mathrm{CH}(15)$ & $2354.1 \pm 55.5$ & $+10.8 \%$ & $2082.7 \pm 146.0 *$ & $-31.5 \%$ \\
\hline $\mathrm{SAL}+\mathrm{SB}(15)$ & $3420.0 \pm 78.1$ & - & $6300.0 \pm 414.1$ & - \\
\hline $\mathrm{SAL}+\mathrm{MDZ}(15)$ & $2516.0 \pm 71.1$ & - & $2892.0 \pm 278.5$ & - \\
\hline SIN-1 + MDZ (15) & $2616.0 \pm 93.3$ & $+4.0 \%$ & $2044.0 \pm 233.3 *$ & $-29.3 \%$ \\
\hline $\mathrm{SAL}+\mathrm{K} / \mathrm{X}(15)$ & $2084.0 \pm 31.2$ & - & $6144.0 \pm 566.3$ & - \\
\hline SIN-1 $(0.1 \mu \mathrm{g})+\mathrm{K} / \mathrm{X}(18)$ & $1970.0 \pm 17.7$ & $-5.5 \%$ & $5726.7 \pm 482.2$ & $-6.8 \%$ \\
\hline
\end{tabular}

Abbreviations: SAL: saline vehicle; SIN-1: 3-morpholinosydnoimine; CH: chloral hydrate; SB: sodium barbital; MDZ: midazolam; K/X: ketamine/xylazine. Significance of difference: *, p < 0.05 (Student's t-test or one way ANOVA), compared to respective SAL + drug control group. 
significantly decreased by exposure to halothane and isoflurane, enzyme activity was not affected by pretreatment with ketamine, pentobarbital, fentanyl and midazolam [6]. Similarly, regional brain NOS activity of rats after intravenous injection of $\left[{ }^{14} \mathrm{C}\right] \mathrm{L}$-arginine was unaltered by treatment with ketamine, thiopental, diazepam and pentobarbital [20]. Rat cerebral cortical and cerebellar levels of $\mathrm{NO}$ - as measured by electron paramagnetic resonance (EPR) spectroscopy-were increased by exposure to halothane, were slightly decreased by ketamine and not appreciably altered by pentobarbital or chloral hydrate [22]. However, NOS activity in rat brain supernatant-measured spectrophotometrically by the NO-mediated conversion of oxyhemoglobin to methemoglobin-was suppressed by addition of thiopental, ketamine, etomidate, or midazolam [8]. Pretreatment with 7-nitroindazole significantly enhanced the duration of methohexital-induced narcosis in rats [23]. Pretreatment with L-NAME also significantly lowered the half-maximal effective concentration $\left(\mathrm{EC}_{50}\right)$ for thiopental-, propofol- and ketamine-induced LORR in Xenopus laevis tadpoles [24].

Our research took a different tack in approaching the issue of NO and anesthesia. Rather than utilizing inhibitors of NO production to assess the effect of NO deficiency on anesthetic endpoints, we decided to centrally administer an NO-donor and assess the influence of NO preloading on LORR. Based on the results of the present study, it is concluded that increasing brain levels of NO shortens the duration-but not latency - of LORR produced by light sedative drugs like chloral hydrate, sodium barbital and midazolam but not deeper sedative or anesthetic drugs like ketamine/xylazine. As the light sedative drugs work primarily through actions on the $\mathrm{GABA}_{\mathrm{A}}$ receptor [25-27] while ketamine works through the NMDA receptor [28], there may be a differential involvement of NO in the LORR response, depending upon whether the primary drug action is through $\mathrm{GABA}_{\mathrm{A}}$ or NMDA receptors.

\section{ACKNOWLEDGEMENTS}

This research was supported in part by an intramural research grant from the WSU College of Veterinary Medicine. None of the authors have any conflict of interest in publishing this research.

\section{REFERENCES}

[1] Zuo, Z.; De Vente, J.; Johns, R.A. Halothane and isoflurane dosedependently inhibit the cyclic GMP increase caused by N-methylD-aspartate in rat cerebellum: novel localization and quantitation by in vitro autoradiography. Neuroscience, 1996, 74, 1069-1075.

[2] Zuo, Z.; Tichotsky, A.; Johns, R.A. Halothane and isoflurane inhibit vasodilatation due to constitutive but not inducible nitric oxide synthase. Implications for the site of anesthetic inhibition of the nitric oxide/guanylyl cyclase signaling pathway. Anesthesiology, 1996, 84, 1156-1165.

[3] Zuo, Z.; Tichotsky, A.; Johns, R.A. Inhibition of excitatory neurotransmitter-nitric oxide signaling pathway by inhalational anesthetics. Neuroscience, 1999, 93, 1167-1172.

[4] Johns, R.A.; Moscicki, J.C.; DiFazio, C.A. Nitric oxide synthase inhibitor dose-dependently and reversibly reduces the threshold for halothane anesthesia: a role for nitric oxide in mediating consciousness? Anesthesiology, 1992, 77, 779-784.

[5] Pajewski, T.; DiFazio, C.; Moscicki, J.C.; Johns R.A. Nitric oxide synthase inhibitors, 7-nitro indazole and nitro ${ }^{\mathrm{G}}$-1-arginine methyl ester, dose dependently reduce the threshold for isoflurane anesthesia. Anesthesiology, 1996, 85, 1111-1119.
[6] Tobin, J.R.; Martin, L.D.; Breslow, M.J.; Traystman, R.J. Selective anesthetic inhibition of brain nitric oxide synthase. Anesthesiology, 1994, $81,1264-1269$.

[7] Galley, H.F.; LeCras, A.E.; Webster, N.R. Anaesthetic agents decrease the activity of nitric oxide synthase from human polymorphonuclear leukocytes. Br. J. Anaesth., 1995, 75, 326-329.

[8] Galley, H.F.; Webster, N.R. Brain nitric oxide synthase activity is decreased by intravenous anesthetics. Anesth. Analg., 1996, 83, 591-594.

[9] Haley, T.J.; McCormick, W.G. Pharmacological effects produced by intracerebral injections of drugs in the conscious mouse. $B r . J$. Pharmacol., 1957, 12, 12-15.

[10] Ichinose, F.; Huang, P.L.; Zapol, W.M. Effects of targeted neuronal nitric oxide synthase gene disruption and nitro G-L-arginine methylester on the threshold for isoflurane anesthesia. Anesthesiology, 1995, 83, 101-108.

[11] Chen, T.Y.; Chang, C.L.; Lan, A.K.; Tseng, C.C.; Tsai, Y.C.; Cheng, J.T. Nitro ${ }^{\mathrm{G}}$-L-arginine methyl ester reduces the minimal alveolar concentration of isoflurane in rabbits. Acta Anaesthesiol. Sin., 1997, 35, 155-159.

[12] Chen, T.Y.; Chang, C.L.; Tseng, C.C.; Tsai, Y.C.; Cheng, J.T. Nitro $^{G}$-L-arginine methyl ester decreases minimum alveolar concentration of isoflurane and reduces brain nitric oxide synthase activity in rats. Acta. Anaesthesiol. Sin., 1998, 36, 127-131.

[13] Fukuda, T.; Saito, S.; Sato, S.; Harukuni, I.; Toyooka, H. Halothane minimum alveolar anesthetic concentration and neuronal nitric oxide synthase activity of the dorsal horn and the locus ceruleus in rats. Anesth. Analg., 1999, 89, 1035-1039.

[14] Engelhardt, T.; Lowe, P.R.; Galley, H.F.; Webster, N.R. Inhibition of neuronal nitric oxide synthase reduces isoflurane MAC and motor activity even in nNOS knockout mice. Br. J. Anaesth., 2006, 96, 361-366.

[15] Kobayashi, S.; Katoh, T.; Iwamoto, T.; Bito, H.; Sato, S. Effect of the neuronal nitric oxide synthase inhibitor 7-nitroindazole on the righting reflex $\mathrm{ED}_{50}$ and minimum alveolar concentration during sevoflurane anaesthesia in rats. Eur. J. Anaesth., 2003, 20, 212219.

[16] Ge, Z,; Tan, Y.; Zhao, Y.; Cui, G. Evidence that inhibition of spinal nitric oxide production contributes to the antinociceptive effects of emulsified isoflurane on formalin-induced pain in rats. Clin. Exp. Pharmacol. Physiol., 2008, 35, 1245-1251.

[17] Adachi, T.; Kurata, J.; Nakao, S.; Murakawa, M.; Shichino, T.; Shirakami, G.; Shinomura, T.; Mori, K. Nitric oxide synthase inhibitor does not reduce minimum alveolar anesthetic concentration of halothane in rats. Anesth. Analg., 1994, 78, 11541157.

[18] Adachi, T.; Shinomura, T.; Nakao, S.; Kurata, J.; Murakawa, M.; Shichino, T.; Seo, N.; Mori, K. Chronic treatment with nitric oxide synthase (NOS) inhibitor profoundly reduces cerebellar NOS activity and cyclic guanosine monophosphate but does not modify minimum alveolar anesthetic concentration. Anesth. Analg., 1995, $81,862-865$.

[19] Tagliente, T.M.; Royal, B.C.; Beasley, J.; Maayani, S. A modified citrulline assay of NOS activity in rat brain homogenates does not detect direct effects of halothane on the kinetics of NOS activity. Brain Res., 1997, 767, 393-396.

[20] Galley, H.F.; LeCras, A.E.; Logan, S.D.; Webster, N.R. Differential nitric oxide synthase activity, cofactor availability and cGMP accumulation in the central nervous system during anaesthesia. Br. J. Anaesth., 2001, 86, 388-394.

[21] Rengasamy, A.; Pajewski, T.N.; Johns, R.A. Inhalational anesthetic effects on rat cerebellar nitric oxide and cyclic guanosine monophosphate production. Anesthesiology, 1997, 86, 689-698.

[22] Sjakste, N.; Baumane, L.; Meirena, D.; Lauberte, L.; Dzintare, M.; Kalvins, I. Drastic increase in nitric oxide content in rat brain under halothane anesthesia revealed by EPR method. Biochem. Pharmacol., 1999, 58, 1955-1959.

[23] Motzko, D.; Glade, U.; Tober, C.; Flohr, H. 7-Nitro indazole enhances methohexital anesthesia. Brain Res., 1998, 788, 353-355.

[24] Tonner, P.H.; Scholz, J.; Lamberz, L.; Schlamp, N.; Schulte, E.J. Inhibition of nitric oxide synthase decreases anesthetic requirements of intravenous anesthetics in Xenopus laevis. Anesthesiology, 1997, 87, 1479-1485.

[25] Gillette, M.A.; Dacheux, R.F. GABA- and glycine-activated currents in the rod bipolar cell of the rabbit retina. J. Neurophysiol., 1995, 74, 856-875. 
[26] Garrett, K.M.; Gan, J.P. Enhancement of $\gamma$-aminobutyric acid receptor activity by $\alpha$-chloralose. J. Pharmacol. Exp. Ther., 1998, 285, 680-686.

[27] McAdam, L.C.; MacDonald, J.F.; Orser, B.A. Isobolographic analysis of the interactions between midazolam and propofol at
$\mathrm{GABA}_{\mathrm{A}}$ receptors in embryonic mouse neurons. Anesthesiology, 1998, 89, 1444-1454.

[28] Thomson, A.M.; West, D.C.; Lodge, D. An N-methyl-D-aspartate receptor-mediated synapse in rat cerebral cortex: a site of action of ketamine? Nature, 1985, 313, 479-481.

(C) Wang et al.; Licensee Bentham Open.

This is an open access article licensed under the terms of the Creative Commons Attribution Non-Commercial License (http://creativecommons.org/licenses/by$\mathrm{nc} / 3.0 /$ ) which permits unrestricted, non-commercial use, distribution and reproduction in any medium, provided the work is properly cited. 